\title{
SÍNDROME DE BURNOUT EN DOCENTES DE EDUCACIÓN BÁSICA Y MEDIA EN TIEMPOS DE CRISIS
}

\section{BURNOUT SYNDROME IN BASIC AND MIDDLE EDUCATION TEACHERS IN TIMES OF CRISIS}

\section{Cesar Augusto Hernández Suárez ${ }^{1}$}

\section{Audin Aloiso Gamboa Suárez²}

Raúl Prada Núñez ${ }^{3}$

Colombia

\section{RESUMEN}

El presente artículo de investigación muestra el análisis de un fenómeno complejo que ha surgido en la comunidad docente relacionada con el agotamiento mental y físico debido a la pandemia causada por la $1 \quad$ Docente investigador de la Universidad Francisco de Paula Santander. Magíster en Enseñanza de las Ciencias por la Universidad Nacional Experimental del Estado Táchira (Venezuela). Correo electrónico: cesaraugusto@ ufps.edu.co, Orcid: 0000-0002-7974-5560.

2 Docente investigador de la Universidad Francisco de Paula Santander. Doctor en Ciencias de la Educación por la Universidad de Cartagena. Correo electrónico: audingamboa@ufps.edu.co, Orcid: 00000001-9755-6408.

$3 \quad$ Docente investigador de la Universidad Francisco de Paula Santander. Magíster en Ingeniería de Análisis de Datos, Mejora de Procesos y Toma de Decisiones por la Universidad Politécnica de Valencia (España). Correo electrónico: raulprada@ufps.edu.co, Orcid: 0000-0001-6145-1786.
Covid-19. El enfoque metodológico se enmarca en el paradigma cuantitativo - transversal. Se elaboró un cuestionario para determinar las afectaciones asociadas con el ejercicio laboral durante el periodo de aislamiento y se aplicó el Maslach Burnout Inventory (MBI) en profesores de educación básica y media de seis instituciones educativas en Norte de Santander. Las conclusiones del estudio demuestran que se han generado conflictos relacionados con el trabajo y la familia. Así mismo se evidenció que los docentes reconocen que no tienen las competencias digitales necesarias para desarrollar sus prácticas pedagógicas de manera adecuada. 


\section{PALABRAS CLAVE:}

agotamiento mental; agotamiento físico; Covid-19; sindrome de Burnout

\section{ABSTRACT}

This research article shows the analysis of a complex phenomenon that has emerged in the teaching community related to mental and physical exhaustion due to the pandemic caused by Covid-19. The methodological approach is framed in the quantitative - transversal paradigm. A questionnaire was developed to determine the effects associated with work exercise during the isolation period, and the Maslach Burnout Inventory (MBI) was applied to elementary and middle school teachers from six educational institutions in Norte de Santander. The conclusions of the study show that conflicts related to work and family have been generated. Likewise, it was evidenced that teachers recognize that they do not have the necessary digital skills to develop their pedagogical practices adequately.

\section{KEYWORDS:}

mental exhaustion; physical exhaustion; Covid-19; Burnout syndrome

\section{INTRODUCCIÓN}

El 19 de febrero del 2020, el brote de la enfermedad Covid-19, causado por el virus SARS-CoV-2, fue declarado pandemia por la Organización Mundial de la Salud (OMS, 2020); razón por la cual se ha visto afectado el sistema social, manifestándose esto "de manera directa en la desaceleración de la economía y en las políticas de ajuste que ello induce.." dichas políticas pueden ser generalizadas en la premura por optar hacía un distanciamiento social como medida para tratar dicha situación global (Eslava, 2020). Asentando la presente disertación en el campo de la educación básica y media, tenemos datos ilustrativos de la situación a nivel global; por ejemplo, el 18 de marzo del año 2020, la Organización de las Naciones Unidas para la Educación, la Ciencia y la Cultura (UNESCO, 2020) estimó que 107 países habían aplicado cierres de instituciones educativas relacionados con la Covid-19, situación que afectaba, para el 2020, a 1600 millones de niños y adolescentes estudiantes, es decir, cerca del $94 \%$ de la población estudiantil del mundo (Naciones Unidas, 2020).

Los cierres de las instituciones educativas (jardines, escuelas, colegios y universidades) se basan en el supuesto de que los brotes de gripe estacionaria (influenza) y coronavirus (Organización Panamericana de la Salud, 2020), se reducen con el distanciamiento social entre los estudiantes y, por lo tanto, se interrumpe su transmisión (Instituto de Salud Carlos III, 2018; Asociación Española de Pediatría, 2010). "Tanto la influenza como la Covid-19 pueden debilitar el sistema inmunológico, haciendo a una persona más susceptible a contraer el otro virus" (Fernández, 2020, párr. 4). Teniendo en cuenta lo anterior, podemos plantear que es por el índice de vulnerabilidad que brinda la Covid-19 en general y porque el crecimiento y desarrollo de los niños y adolescentes es prioridad en materia de percepciones futuras de la sociedad que se hace necesario cerrar dichas instituciones. Como nos dirá la OMS, (2020) "Mejorar la salud y el bienestar durante la niñez y la adolescencia beneficia a las personas a lo largo del ciclo de la vida y a las generaciones venideras." (párr. 4), además, según esta organización, dicha población tiene un devenir incierto, puesto que: "la población de 0 a 18 años se enfrenta a un sinnúmero de nuevas amenazas vinculadas al cambio climático, la contaminación, la mercadotecnia comercial nociva, estilos de vida y dietas poco saludables, traumatismos y violencia, conflictos, migración y desigualdad." (párr. 2), aunque estas no son las únicas amenazas a que se ven expuestos, puesto que, tras la globalización y 
el libre comercio, las conexiones entre países y mercancías han "incrementado la posibilidad de que las enfermedades infecciosas se propaguen rápidamente en todo el mundo" (Alianza para la Protección de la Infancia en la Acción Humanitaria, s.f., p. 7) siendo un caso de esto la Covid-19 y reflejándose en los niños, niñas y adolescentes, desde el punto de vista de la recién mencionada alianza, a través de ciertos campos que los incluyen:

Los niños y niñas, en particular, son vulnerables durante los brotes de enfermedades infecciosas por diferentes motivos. Más allá del efecto inmediato en su salud y la de sus cuidadores, las disrupciones sociales y económicas provocadas por los brotes también presentan riesgos en el bienestar y en la protección de los niños y niñas. Las experiencias aprendidas a través de los brotes, más recientes, es decir el brote de cólera en Yemen en 2016.-2017 y la epidemia de la enfermedad del virus del Ébola (EVE) en África occidental en 2014-2016, nos han enseñado que las respuestas habituales de protección de la niñez y adolescencia, siendo históricamente basadas en contextos de conflictos armados y catástrofes naturales no se adecuan a las situaciones de brotes de enfermedades infecciosas lo que presenta dificultades (p. 7).

El cierre de las instituciones educativas es una intervención no farmacéutica que comúnmente se sugiere para mitigar las pandemias como la influenza (Cauchemez et al., 2009), siendo esta una "enfermedad respiratoria contagiosa provocada por los virus de la influenza que infectan la nariz, la garganta y en algunos casos los pulmones." (Centros para el Control y la Prevención de Enfermedades, [CDC, 2019]). Algunos estudios demuestran que los niños contribuyen más a la transmisión de la gripe que los adultos (Wallinga, Teunis, \& Kretzschmar, 2006), por ejemplo, la Asociación Española de Pediatría [AEPED, s.f.]) afirma que "los niños pequeños son los que a menudo llevan la Gripe a casa y la contagian a las personas mayores con las que conviven." (p. 141). Esto se debe a que si bien la población más propensa a contraer Covid-19 se ha clasificado por edad, o, en otras palabras, a mayor edad, mayor susceptibilidad y aunque "los niños tienen menos probabilidades de enfermar gravemente, no ocurre lo mismo con los adultos que cuidan de ellos. La evidencia sugiere que las escuelas han sido un motor de la segunda ola en Europa y en otros lugares." (Hyde, 2020, párr. 2), dicho autor sentencia que las reaperturas de escuelas no han dado bueno resultados y que "No será posible controlar la pandemia si no abordamos la transmisión por parte de los niños." (párr, 25).

Como data la World Health Organization (2020) "La susceptibilidad a la infección de las personas menores de 20 años es aproximadamente la mitad que la de los adultos de 20 años o más" (p. 9) y, a pesar de que, desde corea, se sugiere que los niños y niñas de 0 a 9 años, tienen una menor tasa de transmisión del virus $(5,3 \%$ son contagios por niños menores de 10 años dentro del hogar); los adolescentes o población entre los 10 y los 19 años de edad presentan el mayor índice de transmisión (18,6\%) la Covid-19 en el ámbito doméstico (Park, et.al., 2020). Lo anterior, refleja que existe una situación de contagio durante las medidas de distanciamiento social como tratamiento de prevención y mitigación para la Covid-19, es decir, en el transcurso del distanciamiento social, se ha podido evidenciar desde ciertos estudios un índice de contagio por relaciones domésticas y que incluso es más alto que el índice de contagio tras relaciones extra domésticas - $11.8 \%$ contagios por contactos en el hogar y el $11.9 \%$ por contactos fuera del hogar -, lo que, según Park, et.al. (2020), permite 
deducir que la "dinámica de transmisión durante el cierre de escuelas" podría estar condicionado por dichos datos.

Entendiendo que los niños y niñas son especialmente susceptibles a las infecciones y que la Covid-19 es causante de una Infección Respiratoria Aguda (IRA) (Minsalud, 2021), entre otras cosas, gracias a que: su "edad, madurez y capacidades de desarrollo" (p. 9) disminuyen las posibilidades de que estos cumplan las exigencias sanitarias; all estado de desarrollo, aún en progreso, de los sistemas inmunitario, nervioso central, reproductivo, digestivo, óseo, muscular, endocrino y otros; a su riesgo particular de desnutrición; y, a que ellos no autorizan libremente sus vacunas y no tienen posibilidad autónoma de tenerlas todas por su edad y dependencia (Alliancecpha, s.f.); debemos dar un enfoque al sistema escolar, teniendo en cuenta el factor social de la educación, donde los niños, niñas y adolescentes interactúan a razón de lo que plantea Echavarría (2003) respecto a la escuela: "escuela como comunidad que convoca y genera adhesión" (párr. 6). Aquí cabe mencionar la relevancia de esta interacción, concordando con el mismo autor, quien concluye que "A través de la interacción con otros es como los sujetos en formación examinan, conocen y viven la cultura, elaboran concepciones del mundo, establecen diversos tipos de relaciones y acceden a sus lógicas" (párr. 6).

Como se ha visto, ciertas decisiones gubernamentales en torno a la actual crisis sanitaria provocada por la Covid-19, han tenido efectos negativos en el contexto educativo, pero el ajuste a las nuevas condiciones no debe dejar atrás la búsqueda de la calidad; es así como se hace necesario "(re)imaginar críticamente el sentido de la educación en el siglo XXI." (Iglesias, et al., 2020, p. 181). Algunos conocimientos y saberes demuestran que no se garantiza la calidad educativa en estas nuevas formas de enseñanza - que abarcan la digitalización y la "adopción masiva de la enseñanza a distancia de manera precipitada" (Iglesias, et al., 2020, p. 182) - como el supuesto de que el impacto en la economía agravará la situación en equidad y disminuirá la oferta y la demanda educativa (Banco Mundial, 2020). Coincidiendo con dicho autor, las Naciones Unidas (2020) señalan que existen problemáticas relacionadas con el acceso a los servicios, para la economía de los padres, respecto a la financiación de la educación, entre otras, afirmando de esta última que "Para los países de ingreso bajo y mediano bajo, por ejemplo, ese déficit ha alcanzado la impactante suma de 148.000 millones de dólares estadounidenses anuales, una suma que podría incrementarse ahora en hasta un tercio." (p. 2); como respuesta a esto, se expone en el mismo texto la respuesta que se le ha dado a tal situación, a saber:

Se han aplicado enfoques innovadores en apoyo de la continuidad de la educación y la formación, recurriendo a la radio y la televisión y a materiales para llevar. Se han desarrollado soluciones educativas a distancia gracias a las rápidas respuestas de Gobiernos y asociados en todo el mundo en apoyo de la continuidad de la educación, como la Coalición Mundial para la Educación reunida por la Organización de las Naciones Unidas para la Educación, la Ciencia y la Cultura (UNESCO) (p. 2).

En materia de inequidad, se evidencia también la exclusión del mundo digital para aquellos estudiantes que no tienen acceso a dichos recursos, reflejándose una vez más la selectividad en pro de las clases sociales más altas, pero que tiene en cuenta a los NNA vulnerables; por ejemplo, Murillo y Duk (2020) aseguran que "Uno de los colectivos que más están sufriendo con la crisis de la Covid-19 y la consecuente clausura de centros educativos 
es el de los niños, niñas y adolescentes en situación de discapacidad" (párr. 6) debido esto, según el mismo autor, a la falta de destrezas o habilidades para manejar las nuevas TIC como herramientas de educación o a que no tienen acceso a los programas y actividades que ofrecen los sistemas. Por otro lado, Iglesias et al. (2020) exponen la situación arraigada tras las nuevas formas de vivir que se han ido construyendo tras la presencia de la Covid-19, dividiendo 4 brechas que se imponen a los niños, niñas y adolescentes actuales:

Una brecha de equipamiento tecnológico (viviendas sin wifi, sin ordenador o compartido para todos los convivientes, con un único dispositivo móvil para toda la familia sujeto a un exiguo plan de datos); habitacional (inadecuación de la vivienda por carencia de espacio, masificación o falta de intimidad); educativa (escaso capital cultural de los padres en el ámbito de la educación formal y/o de los medios digitales) y lingüística (desconocimiento de la lengua vehicular de la escuela por algunas familias, dificultades de comunicación con las maestras y maestros).

Las dinámicas educativas descritas, no solo han afectado los contextos familiares, como lo describe el Fondo de las Naciones Unidas para la Infancia (UNICEF, 2020) al señalar que "La pandemia del Covid-19 y las medidas tomadas por el gobierno para disminuir su propagación han alterado la vida de los hogares con niñas, niños y adolescentes y han generado cambios en los hábitos y rutinas de las personas"(p. 6), ya que, además de el impacto negativo a los ingresos familiares, también se devela dentro del citado texto la presencia de violencia intrafamiliar y un cargo considerable para las mujeres dentro del hogar (Ministerio de las Mujeres, Géneros y Diversidad, 2020 citado en UNICEF, 2020). También el Departamento de Comunicación Global de las Naciones Unidas (s.f.) "Además de agravar el miedo, la ansiedad, el estrés financiero o el consumo de alcohol, la Covid-19 ha puesto a prueba la capacidad de los servicios sanitarios y sociales para comunicarse con las víctimas y apoyarlas." (p. 11). Dicho documento afirma que

En los últimos 12 meses, 243 millones de mujeres y niñas (de edades entre 15 y 49 años) de todo el mundo han sufrido violencia sexual o física por parte de un compañero sentimental. Y, con el avance de la pandemia del Covid-19, es probable que esta cifra crezca con múltiples efectos en el bienestar de las mujeres, su salud sexual y reproductiva, su salud mental y su capacidad de liderar la recuperación de nuestras sociedades y economías, y de participar en ella (párr. 5).

Pero la investigación de dicha violencia, con ambiguos resultados, se desestima durante la pandemia por Covid - 19 puesto que ya no hay redes de apoyo en la comunidad y en los diversos contextos donde normalmente se movilizan los sujetos, como la escuela, el trabajo - la familia extensa, como dice la División de Desarrollo Social de la Comisión Económica para América Latina y el Caribe y las Unidades de Alianzas Públicas y de Protección de la Oficina Regional para América Latina y el Caribe de UNICEF (2020), "En otras palabras, las cifras no hablan de una disminución o un aumento de casos, sino de una disminución de la capacidad de detección" (p. 7). Dicho documento propone a esto "entornos de videoconferencia gratuitos en las comunidades, así como servicios de telecomunicaciones (como llamadas por teléfono celular) gratis entre los miembros de la familia." (p. 13). A manera de recoger lo anterior y agregar el factor socioeconómico y demás factores preexistentes que se ven agravados con 
la llegada de la crisis, la Comisión Económica para América Latina y el Caribe (2020) apunta que

Ante la emergencia actual, las familias no solo enfrentan la pérdida de sus medios de vida y la percepción de menores ingresos, sino que los niños, niñas y adolescentes también encuentran grandes barreras para acceder a la atención sanitaria (incluso a los esquemas de vacunación) y a la educación, con lo que experimentan un mayor riesgo de rezago o abandono escolar. También corren más riesgo de padecer inseguridad alimentaria y de sufrir violencia o maltrato físico. Es urgente, por lo tanto, invertir en la infancia y garantizar su desarrollo en un contexto lleno de adversidades, unas nuevas y otras más antiguas (p. 1).

Las afectaciones también se evidencian en las cargas laborales que han tenido que llevar trabajadores de empresas de los diferentes sectores, tras recurrir al teletrabajo como herramienta de distanciamiento social que los protege del posible contagio por Covid-19, en este caso. Sin embargo, esta misma ventaja del teletrabajo para la sanidad de los trabajadores, se ve como una desventaja en casos donde los trabajadores viven solos y la pérdida de contacto con los compañeros de trabajo (Organización Internacional del Trabajo [OIT, 2020]); también desde dicha organización podemos inferir que el virus "ya ha llevado la capacidad de atención sanitaria más allá de sus límites y ha puesto a los trabajadores de primera línea bajo un riesgo y una presión considerables" (p. 3); dicha presión, debida al "poco tiempo de preparación tanto para los empleadores como para los trabajadores" ( $p$. 3 ), se hace más patente para aquellos países de desarrollo económico menor, aunque ha sido una respuesta útil en países donde la tecnología y las TIC, por ejemplo, se dan por bien servidas; por ejemplo, "En promedio, en Europa, el 24\% de los empleados que nunca habían trabajado desde casa comenzó a teletrabajar, en comparación con el $56 \%$ de los empleados que lo habían hecho ocasionalmente (OIT, 2020, p. $3)$.

Como podemos predecir, para América Latina, el diagnóstico es diferente. Según La CEPAL (2020), la Covid-19 tiene un impacto importante en los países de América Latina y el Caribe y golpea una estructura productiva y empresarial con debilidades que se han originado a lo largo de décadas, dicha comisión económica, amplia esto con la afirmación de que los retos de esta región para los empresarios y trabajadores de las empresas son variados en función de sanidad, ajuste del bien o servicio según las nuevas demandas, capacitación en el uso de nuevas herramientas o el trabajo para la "eficiencia schumpeteriana", capacidad de adquirir y procesar información masiva para su toma de decisiones, mayor producción ya que las importaciones debieron disminuir, etc. Por su parte, el Banco Interamericano de Desarrollo (2019) indica que los retos en las formas de contratación y en alternativas innovadoras de trabajo, se ven mediados en una región donde el estado social de derecho aún es una utopía gracias a la informalidad laboral; evidenciando esto en "la posibilidad de que sus trabajadores no tengan acceso a derechos y garantías fundamentales en el mundo laboral" (p. 5) o en la hipótesis de que en América Latina y el Caribe, como región que ya se encontraba bajo una situación laboral precaria e informal y donde el riesgo actual es de perpetuar dicha situación, "la ventaja competitiva no se da por una mayor productividad, sino evadiendo la legislación laboral y la seguridad social, lo que merma el bienestar de la sociedad." (p. 5). Si nos dirigimos al campo psicológico, podremos entender desde allí la situación actual instada por la pandemia abordada aquí, teniendo en cuenta que "determinados hábitos conductuales, la forma 
cómo evaluamos y afrontamos las múltiples, nuevas, y en constante cambio, demandas ambientales y personales que están presentes en nuestro mundo pueden estar afectando nuestra salud física y/o mental" (Alonso y Cifre, 2002, p. 57). Ahora bien, abordar el teletrabajo desde la psicología, nos revelará ciertos riesgos para la salud del teletrabajador:

[...]ergonomía (ubicación física mal diferenciada del resto de la casa, mala equipación del espacio físico de trabajo, no cumplir las características de temperatura, luz y otras para el adecuado desarrollo del trabajo...), problemas relacionados con los horarios (trabajar poco o en exceso, la no concordancia del horario laboral con los biorritmos naturales del teletrabajador, caos en los horarios de ingesta, sedentarismo y otros...); problemas relacionado con el atuendo (teletrabajar en pijama, no diferenciar el atuendo de las tareas domésticas del teletrabajar); "Síndrome de la patata en el escritorio"; distractores potenciales (otros familiares, enfermos, teléfono, visitas inesperadas...)[...] (Alonso y Cifre, 2002, p.p. 57-58).

Concretamente en el contexto educativo los docentes de todos los niveles se han visto afectados por esta modalidad de trabajo donde tienen retos de adaptación, como docentes, a "Las actividades remotas o de teletrabajo han exigido de los docentes la implementación de varios cambios en lo que se refiere a las estrategias de enseñanza-aprendizaje" (Dos Santos Santiago Ribeiro, Scorsolini-Comin, y Dalri, 2020) pero también como personas en su vida cotidiana; por ejemplo, en el caso de los NNA estudiantes con discapacidad, los docentes tienen un reto, en la medida que "se encuentran absolutamente saturados como para ofrecer la atención más personalizada que muchos de ellos requieren." (Murillo y Duk, 2020, párr. 7) con el abordaje de los cuales después de un prolongado tiempo se muestran síntomas de estrés, fatiga e insatisfacción laboral. Dicho tema es abordado por Dos Santos Santiago Ribeiro, Scorsolini-Comin, \& Dalri, (2020) desde el campo psicológico en la medida que la pandemia representa una exposición sistemática a los riesgos, entre otras cosas, debido a las "horas de trabajo de los docentes vinculados a la educación a distancia, que pueden ir acompañadas de condiciones laborales precarias" (Chaquime y Mill (2016), citado en Dos Santos Santiago Ribeiro, Scorsolini-Comin, \& Dalri, 2020, p. 15), además, en el mismo texto se menciona el papel del teletrabajo para docentes en medio de la pandemia:

Las diversas adaptaciones para el teletrabajo en el contexto de los profesionales de la educación pueden promover el sufrimiento emocional, derivado tanto de las experiencias de aislamiento y distancia social como de la sobrecarga de trabajo devenida de la necesidad de mantener las actividades laborales en el régimen de teletrabajo. De este modo, estas condiciones pueden exponer a los docentes a riesgos que pueden afectar su salud mental durante la pandemia (p. 11).

Los efectos que ha tenido la pandemia sobre el estado emocional de los profesores se puede asociar al síndrome de Burnout, que consiste, según argumentos de Saborío e Hidalgo (2015) a una "inadecuada respuesta al estrés crónico" (párr. 8) de los trabajadores, que denota estresores ante "exigencias y presiones laborales que no se ajustan a sus conocimientos y capacidades" (OMS, 2004, p. 3) se puede inferir del mismo autor que dicha situación se agudiza cuando el trabajador siente que no tiene apoyo en el marco de su trabajo y cuando necesita capacitación o inducción en las diversas tareas y entre sus consecuencias se refleja 
un trabajador más enfermizo, poco motivado, menos productivo, con menor seguridad laboral y puede ser promotor de la poco eficacia de la empresa para la que trabaja (OMS, 2004). En cuanto a las formas de mejorar tal situación se ha visto que "las ocupaciones donde se brindan servicios de salud donde los individuos poseen más posibilidades de desarrollarlo: médicos, enfermeros, odontólogos y psicólogos" (Morales e Hidalgo, 2015, párr. 10) a lo que la OMS (2004) agrega una evaluación de los riesgos, rehabilitación, inversión en la infraestructura necesaria y la adquisición de información desde los trabajadores que pueda ayudar a solucionar la problemática.

En Colombia, los trabajadores se han tenido que ajustar a medidas como el "teletrabajo y "trabajo en casa", estrategias que sin bien tienen aspectos positivos, también han arraigado en un aumento del síndrome por agotamiento por el encierro y por el "tener que ejercer labores propias del hogar, así como, el hecho de adaptarse a estas nuevas condiciones de trabajo, lo que ha provocado un aumento del síndrome de agotamiento en ellos" (De Arco y Castillo, 2020, p. 116). Trabajos como los de Gantiva, Jaimes y Villa (2010) que a través de su aporte a la noción del síndrome de Burnout (SB) "el burnout no es un proceso asociado a la fatiga, sino a la desmotivación emocional y cognitiva que sigue al abandono de intereses que en un determinado momento fueron importantes para el sujeto" - concluyen que los síntomas de dicho síndrome se intensifican el los grados sexto y octavo, ya que estos "presentan mayores niveles de agotamiento emocional y despersonalización y menores niveles de realización personal (ver tabla 2), en comparación con los otros grupos. Estos resultados están relacionados con la etapa de desarrollo en la que se encuentran los niños" (p. 47); además, dichos autores coinciden con Upegui y Zuluaga (2020) al clasificar a los docentes como profesionales vulnerables al desarrollo del SB, puesto que estos "en su quehacer tienen interacción diaria con otras personas o que sus servicios impactan directamente en la vida de otros" (p. 4); dichas autoras orientan su respuesta a dicho síndrome, mediante la sensibilización y el empoderamiento, en base al conocimiento de los implicados, para detener las implicaciones del trastorno en sus vidas.

Aquí, cabe mencionar la contribución de Correa, Muñoz y Zapata (2010), quienes encuentra que "la dimensión despersonalización solo está en los docentes que laboran tiempo completo y que manifestaron pasar más del $75 \%$ de su tiempo con los beneficiarios de sus servicios, de igual manera presentaron mayor presencia de consecuencias físicas y sociales."(párr, 27) además de una existencia considerable de despersonalización, es decir, actitudes negativas e inestables hacia los agentes de su entorno laboral, en la población más joven (entre 20 y 40 años), así como una "presencia importante de altas consecuencias físicas y sociales en los docentes, que en el tiempo si no se intervienen pueden predisponer a un estrés crónico y por ende a que se presente el síndrome de Burnout." (párr. 30). A continuación, se presenta entonces una exposición de la situación para los docentes en materia del síndrome de Burnout:

continuamente se exponen a situaciones estresantes propias del entorno en el cual desarrollan su quehacer profesional, aunado a esto, el entorno social cambiante y la transformación metodológica que viene sufriendo la educación como causa de la misma evolución y las nuevas dinámicas de enseñanza aprendizaje, han traído consigo una serie de retos que en ocasiones parece desbordar la capacidad y el tiempo de las personas que ejercen esta profesión (Upegui y Zuluaga, 2020. p. 48). 
En el caso concreto de la Pandemia de la Covid-19 y su relación con el síndrome de Burnout, es prolifera la literatura que se ha publicado en el último año. Estudios como los de Ortiz (2020) significan el rol de los docentes en la pandemia, proyectándolos no solo como creadores de estrategias educativas que tengan en cuenta las TIC, sino como agentes de acompañamiento a estudiantes y que guardan la esperanza de que el distanciamiento sea físico más no afectivo: "Estamos en la primera línea de la experiencia emocional de los niños, niñas y jóvenes. No somos indiferentes. Captamos sus necesidades emocionales al igual que médicos y enfermeras captan signos vitales" (párr. 10). De igual forma Parra, Chaves y Zea (2020) definen genéricamente la situación de los docentes instada por la pandemia de la Covid-19:

Los docentes para cumplir con su práctica educativa, además de realizar sus actividades normales han tenido que habituarse al uso de herramientas tecnológicas, y plataformas que probablemente no utilizaban o no conocían, existen en algunos además de estas inquietudes, presiones emocionales por el confinamiento, en otros una gran preocupación por su salud y la de su familia; lo que puede provocar estrés o síndrome de burnout. (p. 31).

Por lo descrito en los párrafos anteriores, se hace necesario realizar un diagnóstico sobre los efectos que ha generado las nuevas formas educativas en tiempos de crisis y de esta manera brindar información actualizada a directivos docentes para que se generen acciones para contrarrestar este fenómeno desde los planes de acción institucionales que beneficien la calidad de los docentes.

\section{MÉTODO}

El presente estudio se enmarca en el paradigma cuantitativo - transversal y se realizó con docentes de seis instituciones educativas pertenecientes a la Secretaria de Educación de Norte de Santander, Colombia.

Se elaboró un cuestionario para determinar los datos sociodemográficos y los relacionados con el ejercicio laboral durante el periodo de aislamiento y los recursos con los que contó para afrontarlo (sobrecarga de trabajo - 3 ítems, conflicto entre el trabajo y la familia - 3 ítems, uso y desarrollo de competencias TIC - 5 ítems y el apoyo por parte de sus superiores, colegas y familiares -3 ítems) medidos en rangos de bajo y alto.

Para determinar el sindrome de Burnout en los docentes objeto de estudio se utilizó el Maslach Burnout Inventory (MBI), el cual está constituido por 22 ítems (con rangos de medida de frecuencia desde 0 para el caso de Nunca, hasta 6 para la opción de Todos los días) en forma de afirmaciones, sobre los sentimientos y actitudes del profesional en su trabajo y hacia los estudiantes, con el objetivo de medir el desgaste profesional. El inventario pretende medir la frecuencia y la intensidad con la que se sufre el sindrome. Esta versión mantuvo la tridimensionalidad del modelo teórico de Maslach (Maslach \& Jackson, 1986) y evalúa el síndrome de Burnout a través de sus tres dimensiones (Martínez, 2010) tal como visualiza en la Tabla 1. 
Tabla 1. Dimensiones del Maslach Burnout Inventory

\begin{tabular}{|c|c|c|c|}
\hline Dimensiones & Definición & ítems & $\begin{array}{l}\text { Puntuación } \\
\text { máxima }\end{array}$ \\
\hline $\begin{array}{l}\text { Cansancio Emocional } \\
\text { (CE) }\end{array}$ & $\begin{array}{l}\text { Valora la vivencia de estar } \\
\text { exhausto emocionalmente por } \\
\text { las demandas del trabajo }\end{array}$ & $\begin{array}{c}9 \text { ítems } \\
(1,2,3,6,8,13 \\
14,16,20 .)\end{array}$ & 54 \\
\hline $\begin{array}{l}\text { Despersonalización } \\
\text { (DP) }\end{array}$ & $\begin{array}{l}\text { Valora el grado en que cada } \\
\text { uno reconoce actitudes frialdad } \\
\text { y distanciamiento }\end{array}$ & $\begin{array}{c}\text { ítems } \\
(5,10,11,15,22 .)\end{array}$ & 30 \\
\hline $\begin{array}{l}\text { Realización Personal } \\
\text { (RP) }\end{array}$ & $\begin{array}{l}\text { Evalúa los sentimientos de } \\
\text { autoeficiencia y realización } \\
\text { personal en el trabajo }\end{array}$ & $\begin{array}{c}8 \text { ítems } \\
(4,7,9,12,17,18, \\
19,21 .)\end{array}$ & 48 \\
\hline
\end{tabular}

El instrumento fue validado en Colombia en el 2004 y mostró valores del índice alfa de Cronbach aptos para el agotamiento emocional $(0,62)$ y la despersonalización $(0,72)$ y satisfactorios para el sentimiento de realización personal $(0,76)$ tal como se cita en RestrepoAyala, Colorado-Vargas y Cabrera-Arana (2006).

Se logró conformar un grupo de 125 docentes mediante la aplicación del muestreo no probabilístico, los cuales diligenciaron el cuestionario en línea durante el mes de marzo del 2021. Los análisis se realizaron con el software estadístico SPSS versión 25. Se estableció una asociación entre el Burnout y las variables sociodemográficas. Para determinar los posibles factores de riesgo del sindrome de Burnout en los participantes, se realizó un análisis de las asociaciones entre las variables sociodemográficas y las relacionadas con el ejercicio laboral durante el periodo de aislamiento con los resultados se presentan en forma de razón de probabilidades con un intervalo de confianza del 95\%.

\section{RESULTADOS}

Características demográficas de los demográficas, la edad media fue de 36,8 años, con una edad mínima de 20 años y una edad máxima de 65 años, destacando que el 58,4\% tienen entre 20 y 40 años. La proporción de sexo fue del $56,8 \%$ que corresponden al género femenino y el resto al masculino. Respecto a los años de experiencia docente, se pudo determinar que el promedio del grupo de encuestados es de 19,3 años, destacando que el $75,2 \%$ de cuentan con menos de 20 años de estar laborando como docentes. Finalmente, en cuanto al estado civil, se identificó que el $73,6 \%$ están casados o tienen pareja estable (ver Tabla 2). 
Tabla 2. Características sociodemográficas de los docentes

\begin{tabular}{|c|c|c|c|}
\hline Variable & Opciones de respuesta & Número de docentes & Porcentaje \\
\hline \multirow{3}{*}{ Edad } & Entre 20 y 40 años & 73 & $58,4 \%$ \\
\hline & Entre 41 y 65 años & 52 & $41,6 \%$ \\
\hline & Total & 125 & $100,0 \%$ \\
\hline \multirow{3}{*}{ Genero } & Femenino & 71 & $56,8 \%$ \\
\hline & Masculino & 54 & $43,2 \%$ \\
\hline & Total & 125 & $100,0 \%$ \\
\hline \multirow{3}{*}{ Estado civil } & $\begin{array}{l}\text { Casado (incluye unión } \\
\text { libre) }\end{array}$ & 92 & $73,6 \%$ \\
\hline & Divorciado & 33 & $26,4 \%$ \\
\hline & Total & 125 & $100,0 \%$ \\
\hline \multirow{3}{*}{$\begin{array}{l}\text { Años de experiencia } \\
\text { docente }\end{array}$} & Menos de 20 años & 94 & $75,2 \%$ \\
\hline & 20 años o más & 31 & $24,8 \%$ \\
\hline & Total & 125 & $100,0 \%$ \\
\hline
\end{tabular}

Características relacionadas con el ejercicio laboral durante el aislamiento. En cuanto a las características relacionadas con el ejercicio laboral durante el aislamiento por medio de la Tabla 3, se puede observar que el $55,2 \%$ percibió una gran carga de trabajo, el
$56,0 \%$ declaró tener un conflicto trabajo-familia, el $48,8 \%$ no ha utilizado ni desarrollado mucho sus competencias TIC y el $81,6 \%$ percibió un escaso apoyo por parte de sus superiores, colegas e incluso familiares.

Tabla 3. Características relacionadas con el trabajo durante el aislamiento

\begin{tabular}{|c|c|c|c|}
\hline Variable & Opciones de respuesta & $\begin{array}{l}\text { Número de } \\
\text { docentes }\end{array}$ & Porcentaje \\
\hline \multirow{3}{*}{ Carga laboral } & Alta & 69 & $55,2 \%$ \\
\hline & Baja & 56 & $44,8 \%$ \\
\hline & Total & 125 & $100,0 \%$ \\
\hline \multirow{3}{*}{$\begin{array}{l}\text { Conflictos entre el trabajo y la } \\
\text { familia }\end{array}$} & Alto & 70 & $56,0 \%$ \\
\hline & Bajo & 55 & $44,0 \%$ \\
\hline & Total & 125 & $100,0 \%$ \\
\hline \multirow{3}{*}{$\begin{array}{l}\text { Utilización y desarrollo de } \\
\text { competencias TIC }\end{array}$} & Alto & 64 & $51,2 \%$ \\
\hline & Bajo & 61 & $48,8 \%$ \\
\hline & Total & 125 & $100,0 \%$ \\
\hline \multirow{3}{*}{$\begin{array}{l}\text { Apoyo por parte de sus } \\
\text { superiores, colegas y } \\
\text { familiares }\end{array}$} & Alto & 23 & $18,4 \%$ \\
\hline & Bajo & 102 & $81,6 \%$ \\
\hline & Total & 125 & $100,0 \%$ \\
\hline
\end{tabular}


Burnout Académico. Se utilizó el Análisis de Componentes Principales (ACP) dado que es una técnica matemática que no requiere del supuesto de normalidad multivariante de los datos (Díaz Rodríguez et al., 2020), con rotación VARIMAX para el Maslach Burnout Inventory de 22 ítems, específico para los docentes de la muestra, distribuidos en tres dimensiones principales, que explican el $71,9 \%$ de la varianza: Cansancio emocional (9 ítems), despersonalización (5 ítems) y sentido de realización personal (8 ítems). Los coeficientes de consistencia interna fueron todos satisfactorios tal como se muestra en la Tabla 4.

Tabla 4. Índice Alfa de Cronbach para las subescalas de Maslach Burnout Inventory

\begin{tabular}{|l|c|}
\hline \multicolumn{1}{|c|}{ Subescala } & Índice Alfa de Cronbach \\
\hline Cansancio Emocional - CE & 0,91 \\
\hline Despersonalización - DP & 0,69 \\
\hline Realización Personal - RP & 0,83 \\
\hline
\end{tabular}

Para las tres dimensiones del Burnout las puntuaciones medias fueron: de 20,8 para el CE, de 11,1 para la DP y de 13,1 para la RP. En todos los tres casos, la variabilidad de los datos recolectados osciló entre el $12,5 \%$ y el $28,5 \%$, siendo los ítems asociados a la subescala de la despersonalización quienes presentaron la mayor dispersión.

Patológicamente, el cansancio emocional alcanzó el nivel de alto en el $24,0 \%$ de los casos, mientras que para la despersonalización el nivel alto se observó en el 9,6\% de los encuestados; finalmente, en lo que respecta a la dimensión de Realización Personal se determinó que el $39,2 \%$ de los docentes encuestados aseguran que con la declaratoria de pandemia han alcanzo nivel de auto realización altos dado que han tenido que incursionar en la utilización de

Tabla 5. Parámetros estadísticos de las dimensiones del burnout en los docentes

\begin{tabular}{|l|c|c|c|}
\hline \multicolumn{1}{|c|}{ Dimensión } & Puntuación media & Deviación Estándar & Casos patológicos \\
\hline Cansancio Emocional & 20,8 & 8,8 & 30 \\
\hline Despersonalización & 11,1 & 9,0 & 12 \\
\hline Realización Personal & 13,1 & 6,0 & 49 \\
\hline
\end{tabular}

Asimismo, el Maslach Burnout Inventory reveló que 68 profesores (equivalente al $54,4 \%$ ) eran víctimas del Burnout, distribuidos de la siguiente forma según el nivel de afectación: el $37,6 \%$ se ubican en el nivel bajo, el $12,0 \%$ en nivel moderado y el $4,0 \%$ en el nivel severo.

En cuanto a la relación entre las variables sociodemográficos y el Burnout, la prueba de Chi-Cuadrado mostró que el género y el estado civil no tienen una relación significativa con el síndrome, mientras que la edad se asoció significativamente, especialmente los docentes mayores de 40 años manifestaron estar más agotados (). Los años de experiencia docente también se asoció significativamente con el Burnout, determinando que los profesores con más de 20 años de antigüedad fueron los más agotados () (ver Tabla 6). 
Tabla 6. Asociación del burnout con las características sociodemográficas de los docentes

\begin{tabular}{|c|c|c|c|c|c|}
\hline Variable & $\begin{array}{l}\text { Opciones de } \\
\text { respuesta }\end{array}$ & $\begin{array}{l}\text { Burnout } \\
\text { efectivo }\end{array}$ & Porcentaje & Chi-cuadrado & $\mathrm{p}$-valor \\
\hline \multirow{2}{*}{ Edad } & $\begin{array}{l}\text { Entre } 20 \text { y } 40 \\
\text { años }\end{array}$ & 32 & $47,1 \%$ & \multirow{2}{*}{6,32} & \multirow{2}{*}{$0,009^{* *}$} \\
\hline & $\begin{array}{c}\text { Entre } 41 \text { y } 65 \\
\text { años }\end{array}$ & 36 & $52,9 \%$ & & \\
\hline \multirow{2}{*}{ Genero } & Femenino & 42 & $61,7 \%$ & \multirow{2}{*}{1,83} & \multirow{2}{*}{ N.S. } \\
\hline & Masculino & 26 & $38,3 \%$ & & \\
\hline \multirow{2}{*}{ Estado civil } & Casado & 55 & $80,9 \%$ & \multirow{2}{*}{2,02} & \multirow{2}{*}{ N.S. } \\
\hline & Divorciado & 13 & $13,1 \%$ & & \\
\hline \multirow{2}{*}{$\begin{array}{l}\text { Experiencia } \\
\text { Docente }\end{array}$} & $\begin{array}{c}\text { Menos de } 20 \\
\text { años }\end{array}$ & 45 & $66,2 \%$ & \multirow[t]{2}{*}{5,54} & \multirow[t]{2}{*}{$0,015^{*}$} \\
\hline & 20 años o más & 23 & $33,8 \%$ & & \\
\hline
\end{tabular}

N.S.: No significativo; *: Estadísticamente significativo al nivel del $5 \%$; **: Estadísticamente significativo al nivel del $1 \%$

En cuanto a las variables relacionados con el ejercicio laboral durante el periodo de confinamiento, la prueba de Chi-Cuadrado mostró que el agotamiento de los docentes estuvo significativamente relacionado con cada una de las categorías asociadas con la actividad laboral de los docentes, resaltando que en todos los casos la relación fue altamente significativa, es decir, al nivel de significancia bilateral del $1 \%$, tal como se muestra en la Tabla 7.

Tabla 7. Asociación del Burnout con las características laborales de los docentes

\begin{tabular}{|c|c|c|c|c|c|}
\hline Categoría & $\begin{array}{l}\text { Opciones de } \\
\text { respuesta }\end{array}$ & $\begin{array}{l}\text { Burnout } \\
\text { efectivo }\end{array}$ & Porcentaje & Chi-cuadrado & $\mathrm{p}$-valor \\
\hline \multirow{2}{*}{ Carga Laboral } & Alta & 48 & $70,6 \%$ & \multirow{2}{*}{7,11} & \multirow[t]{2}{*}{$0,006^{* *}$} \\
\hline & Baja & 20 & $29,4 \%$ & & \\
\hline \multirow{2}{*}{$\begin{array}{l}\text { Conflictos } \\
\text { entre el } \\
\text { trabajo y la } \\
\text { familia }\end{array}$} & Alta & 46 & $67,5 \%$ & \multirow[b]{2}{*}{6,09} & \multirow{2}{*}{$0,01^{* *}$} \\
\hline & Baja & 22 & $32,5 \%$ & & \\
\hline \multirow{2}{*}{$\begin{array}{c}\text { Use y } \\
\text { Desarrollo de } \\
\text { competencias } \\
\text { TIC }\end{array}$} & Alta & 27 & $39,7 \%$ & \multirow[b]{2}{*}{7,89} & \\
\hline & Baja & 41 & $60,3 \%$ & & $0,001^{* *}$ \\
\hline \multirow{2}{*}{$\begin{array}{l}\text { Apoyo por } \\
\text { parte de sus } \\
\text { superiores, } \\
\text { colegas y } \\
\text { familiares }\end{array}$} & Alta & 5 & $7,4 \%$ & \multirow[b]{2}{*}{12,12} & \multirow[b]{2}{*}{$0,000^{* *}$} \\
\hline & Baja & 63 & $92,6 \%$ & & \\
\hline
\end{tabular}




\section{CONCLUSIONES Y DISCUSIÓN}

El presente estudio relacionado con el Sindrome de Burnout en docentes de educación básica y media revela que un porcentaje importante de la muestra (55.2\%) ha percibido una gran carga de trabajo en el periodo de aislamiento causado por la pandemia de la Covid-19. Estos resultados se contrastan con los estudios de Medina et al., (2021) y López et al., (2021) quienes manifiestan que las afectaciones personales, en particular el exceso de carga laboral están determinadas principalmente por el cambio de modalidad presencial a virtual realizada en los hogares. Estas afectaciones se manifiestan a través de constantes interrupciones laborales en sus espacios personales lo que aumenta los sentimientos de estrés y frustración en los docentes (López et al., 2021, p. 38).

Otro elemento relevante que se logró identificar en la investigación, es el conflicto trabajo - familia. Los participantes del estudio reconocen categóricamente que el trabajo en casa ha deteriorado el clima familiar debido a la no compatibilidad de los dos escenarios y las diferencias en la responsabilidad que ambos roles demandan. De este modo, trabajos como los de Santillán (2020), demuestran que gran parte de los conflictos de familia - trabajo se generan por la no conciliación entre los miembros del grupo familiar para planificar, organizar tareas y administrar los tiempos para el trabajo autónomo.

Un aspecto importante para resaltar es la relación entre el Sindrome de Burnout y el uso adecuado de las tecnologías digitales. En este sentido, Macias et al., (2021) ponen de manifiesto que el desarrollo de las competencias digitales en docentes, ha sido uno de los retos más complejos que han tenido que superar los maestros en tiempos de pandemia y en mayor medida lo relacionado con la creación de contenidos para atender a la diversidad de los aprendizajes de los estudiantes durante la emergencia.

Por último, es importante señalar que la protección de los docentes en esta situación de pandemia debe ser un componente importante en las medidas de salud pública para combatir las consecuencias de la Covid-19 en su salud mental y física. La intervención para promover el bienestar mental de los profesores durante y después del confinamiento deben implementarse los más pronto posible en las instituciones educativas de todos los niveles.

\section{REFERENCIAS BIBLIOGRÁFICAS}

Alianza para la Protección de la Infancia en la Acción Humanitaria. (s.f.). Nota de orientación: Protección A niños, niñas $y$ adolescentes durante los brotes de enfermedades infecciosas (1-52). Recuperado de: https://alliancecpha.org/ en/system/tdf/library/attachments/ido_ spanish_version.pdf?file=1\&type=node \& id $=37715$

Alonso, F., y Cifre, E (2002). Teletrabajo y Salud: un nuevo reto para la Psicología. Papeles del Psicólogo, (83), 55-61. Recupearado de: $\quad$ https://www.redalyc.org/articulo. oa?id=77808308

Asociación Española de Pediatría. (s.f). Gripe. (141 - 160). Recuperado de: https://www. aeped.es/sites/default/files/documentos/ gripe.pdf

Banco Interamericano de Desarrollo. (2019). El futuro del trabajo en América Latina y el Caribe ¿Cómo garantizar los derechos de los trabajadores? Doi: http://dx.doi. org/10.18235/0002087 
Banco Mundial. (2020). Covid-19: Impacto En La Educación y Respuestas De Política Pública. 1 - 10. Recuperado de: $\quad$ https://pubdocs.worldbank.org/ en/143771590756983343/Covid-19Education-Summary-esp.pdf

Centros para el Control y la Prevención de Enfermedades (2019). Datos clave sobre la influenza. Recuperado de: https:// espanol.cdc.gov/flu/about/keyfacts.htm

Comisión Económica para América Latina y el Caribe y la Oficina Regional para América Latina y el Caribe del Fondo de las Naciones Unidas para la Infancia (2020). Protección social para familias con niños, niñas $y$ adolescentes en América Latina y el Caribe Un imperativo frente a los impactos del Covid-19. 1 - 21. Recuperado de: https://www.cepal.org/ sites/default/files/publication/files/46489/ S2000745_es.pdf

Comisión Económica para América Latina y el Caribe. (2020). Sectores y empresas frente al Covid-19: emergencia y reactivación (4). Barcena, A (Dir). 1 - 23. Recuperado de: https://repositorio.cepal. org/bitstream/handle/11362/45734/4/ S2000438 es.pdf

Correa-Correa, Z., Muñoz-Zambrano, I., \& Chaparro, A. F. (2010). Síndrome de Burnout en docentes de dos universidades de Popayán, Colombia. Revista de Salud Pública, 12(4), 589-598. Recuperado de https://revistas.unal.edu.co/index.php/ revsaludpublica/article/view/32914

De Arco, L. y Castillo, J. (2020). Síndrome de Burnout en época de pandemia: caso colombiano. Interconectando Saberes 10 (5). 115 - 123. Doi: https://doi. org/10.25009/is.v0i10.2675
Díaz Rodríguez, A. M., Cogollos Martínez, J. B., Peña Acción, J., Cogollos Izaguirre, A., \& González Álvarez, R. (2020). Modelo matemático para predecir el consumo de energía eléctrica en la Universidad de Cienfuegos. Universidad Y Sociedad, 12(4), 21-31. Recuperado de https:// rus.ucf.edu.cu/index.php/rus/article/ view/1608

División de Desarrollo Social de la Comisión Económica para América Latina y el Caribe y las Unidades de Alianzas Públicas y de Protección de la Oficina Regional para América Latina y el Caribe del Fondo de las Naciones Unidas para la Infancia (2020). Violencia contra niñas, niños $y$ adolescentes en tiempos de Covid-19. (p.p. 1 - 17). Recuperado de: https://www.cepal.org/sites/default/files/ publication/files/46485/S2000611_es.pdf

Dos Santos Santiago Ribeiro, B. M., ScorsoliniComin, F., \& Dalri, R. de C. de M. B. (2020). Ser docente en el contexto de la pandemia de Covid-19: reflexiones sobre la salud mental. Index De Enfermería, 29(3), 137-141. Recuperado de: http:// ciberindex.com/c/ie/e12983

Echavarría Grajales, C. V. (2011). La escuela un escenario de formación y socialización para la construcción de identidad moral. Revista Latinoamericana De Ciencias Sociales, Niñez Y Juventud, 1(2), 1-26. Recuperado de: http://revistaumanizales. cinde.org.co/rlcsnj/index.php/RevistaLatinoamericana/article/view/332 .

El Fondo de las Naciones Unidas para la Infancia. (2020). Encuesta de Percepción y Actitudes de la Población. Impacto de la pandemia Covid-19 y las medidas adoptadas por el gobierno sobre la vida cotidiana. Waisgrais, S (ed.). Argentina. 
Recuperado de: https://www.unicef.org/ argentina/media/8646/file/tapa.pdf

Fernández, J. (29 de September de 2020). La temporada de influenza 2020 ya está aquí y vacunarse ahora es más importante que nunca debido a la pandemia de la Covid-19. En Baptist Health South Florida. Recuperado de: https://baptisthealth.net/ baptist-health-news/es/la-temporadade-influenza-durante-la-covid-19-lo-queusted-debe-saber-ahora/

Gantiva Diaz, C. A., Jaimes Tabares, S., \& Villa Orozco, M. C. (2010). Síndrome de Burnout y estrategias de afrontamiento en docencia de primaria y bachillerato. Psicología Desde El Caribe, 36-50. Recuperado de: http://rcientificas. uninorte.edu.co/index.php/psicologia/ article/view/896

Hyde, Z (29 de noviembre del 2020). Los niños pueden transmitir el coronavirus igual que los adultos, según los últimos estudios. En The Conversation. Academic rigor, journalistic flair. Recuperado de: https:// theconversation.com/los-ninos-puedentransmitir-el-coronavirus-igual-que-losadultos-segun-los-ultimos-estudios151073\#: :text=Es $\% 20$ probable $\% 20$ que \% 20 l os \% 20 ni \% C $3 \%$ B 1 os ,Europa $\% 20$ y $\% 20$ en $\% 20$ otros $\% 20$ lugares

Iglesias, E., Gonzáles, J., Lalueza, J. y Guitart, M. (2020). Manifiesto en Tiempos de Pandemia: Por una Educación Crítica, Intergeneracional, Sostenible y Comunitaria. Revista Internacional de Educación para la Justicia Social, 9(3e), 181-198. Doi: https://doi.org/10.15366/ riejs2020.9.3.010

López, G. G., Vásquez, A., Caviativa, Y. P., Ospina, P. A., Chaves, V. T., Carreño,
L. M., \& Vera, V. J. (2021). Tensiones y realidades de los docentes universitarios frente a la pandemia Covid-19. European Journal of Health Research, 7(1), 1-13. DOI: $\quad$ https://doi.org/10.32457/ejhr. v7i1.1396

Martínez, A. (2010). El síndrome de Burnout. Evolución conceptual y estado actual de la cuestión. Vivat Academia, (112), 42-80. Recuperado de: https://doi.org/10.15178/ va.2010.112.42-80

Maslach, C. \& Jackson, S.E. (1986): The Maslach Burnout Inventory. Palo Alto, California: Consulting Psychologists Press.

Macías-Figueroa, F. M., Mendoza-Vergara, G. M., Mieles-Pico, G. L., \& San AndrésSoledispa, E. J. (2021). Competencias digitales del docente para atender a la diversidad de aprendizajes en la pandemia COVID-19. Polo del Conocimiento, 6(1), 288-306. Recuperado de: https:// polodelconocimiento.com/ojs/index.php/ es/article/view/2142

Medina-Guillen, L. F., Quintanilla-Ferrufino, G. J., Palma-Vallejo, M., \& Guillen, M. F. M. (2021). Carga laboral en un grupo latinoamericano de docentes durante la pandemia de COVID-19. Uniciencia, 35 (2), 1-16. Doi: https://dx.doi.org/10.15359/ ru. $35-2.15$

Murillo, F. Javier, \& Duk, Cynthia. (2020). El Covid-19 y las Brechas Educativas. Revista latinoamericana de educación inclusiva, 14(1), 1113. Recuperado de: https://dx.doi. org/10.4067/S0718-73782020000100011

Naciones Unidas (2020). Informe de políticas: La educación durante la COVID-19 y después de ella. 1 - 29. Recuperado 
de: https://www.un.org/sites/un2.un.org/ files/policy_brief_-_education_during_ covid-19_and_beyond_spanish.pdf

Oficina Internacional del Trabajo (2020). El teletrabajo durante la pandemia de COVID-19 y después de ella - Guía práctica. Ginebra: OIT. 1- 45. Recuperado de: https://www.ilo.org/wcmsp5/groups/ public/---ed_protect/---protrav/---travail/ documents/publication/wcms_758007.pdf

Organización Mundial de la Salud. (19 de noviembre del 2020). Nuevas amenazas para la salud de los niños y los adolescentes. Organización Mundial de la Salud. Recuperado de: https://www. who.int/es/news-room/fact-sheets/detail/ children-new-threats-to-health

Organización Munidal de la Salud. (2004). La Organización del Trabajo y el Estrés. Serie de protección de la salud de los trabajadores (3). (p.p. 1 - 27) Francia. Recuperado de: https://www.who. int/occupational_health/publications/ pwh3sp.pdf?ua=1

Ortiz, J. (23 de abril del 2020). Los docentes en la primera línea emocional de la pandemia. NovaEt Vetera. Recuperado de: https:// www.urosario.edu.co/PeriodicoNovaEtVetera/Salud/Los-docentes-en-laprimera-linea-emocional-de-la-p/

Park, Y., Choe, Y., Park, O., Park, S., Kim, Y., Kim, J .... Jeong, E. (2020). Seguimiento de contactos durante el brote de enfermedad por coronavirus, Corea del Sur, 2020. Enfermedades infecciosas emergentes, 26 (10), 2465-2468. Doi: $\quad$ https://dx.doi.org/10.3201/ eid2610.201315

Parra, R., Chávez, Hy Zea, A. (2020). El síndrome de burnout en el personal docente de la Unidad Académica del Norte del Estado de
Nayarit. Análisis comparativo 2018-2020. Revista de Educación Superior (4)12. 31-38. Doi: https://dx.doi.org/10.35429/ JHS.2020.12.4.31.38

Restrepo-Ayala, N. C., Colorado-Vargas, G. O., \& Cabrera-Arana, G. A. (2006). Desgaste emocional en docentes oficiales de Medellín, Colombia, 2005. Revista de Salud Pública, 8, 63-73. Doi: https://www. redalyc.org/pdf/422/42280106.pdf

Saborío, L., e Hidalgo, L. (2015). Síndrome de Burnout. Medicina Legal de Costa Rica, 32 (1), 19-124. Recuperado de: $\quad$ http://www.scielo.sa.cr/scielo. php?script=sci_arttext $\&$ pid $=$ S1409$00152015000100014 \&$ lng=en\&tIng=es

Santillan, W. (2020). El teletrabajo en el COVID-19. CienciAmérica: Revista de divulgación científica de la Universidad Tecnológica Indoamérica, 9(2), 65-76. Recuperado de: https://dialnet.unirioja.es/ servlet/articulo?codigo $=7746439$

Upegui, E y Zuluaga, B. (2020). Estrategias para la prevención del síndrome de Burnout en los docentes de educación media del Taller Psicopedagógico de los Andes. [Trabajo de grado]. Universidad Cooperativa De Colombia. Bogotá, Colombia.

World Health Organization. (2020). Lo que se sabe sobre la transmisión de la Covid-19 en las escuelas. Últimas Noticias Sobre La Situación Global Del Covid-19 y La Propagación Del Covid-19 En Las Escuelas. (1-32). Recuperado de: https://www.who.int/docs/defaultsource/coronaviruse/risk-commsupdates/update39_covid19-and-schools_ es.pdf?sfvrsn=9f587665_4 